however, is usually caused by an alteration in the effectiveness of the catalytic process rather than of the binding.

of greater interest is the possible relation between this autoinhibitory effect and the blockade observed physiologically when neuromuscular preparations are exposed to high concentrations of acetylcholine-the phenomenon of "desensitization". Classical drug-receptor theory supposes that drug effects are a consequence of a change in the receptor to an "active" form, induced by binding of the agonist. On this basis, desensitization has been interpreted as being caused by the formation of "inactive" acetylcholine-receptor complexes, with a reduced ability to generate a physiological response. Receptors can thus exist in two forms, effective- $\mathbf{R}$, at low ACh concentrations of acetylcholineand desensitized- $\mathbf{R}^{\prime \prime}$, at high concentrations of acetylcholine. The model also assumes that the affinity of $\mathbf{R}^{\prime \prime}$ for acetylcholine is lower than that of $\mathbf{R}$, but suggests no explanation of how these changes are brought about.

Eldefrawi and O'Brien propose a scheme whereby receptors may possess more than one type of binding site, occupation of low affinity sites leading to a reduction in binding to the high affinity or active sites and ultimately to a conformational change in the receptor, such that the affinity of the active sites for acetylcholine is decreased greatly. This would provide an attractive explanation for the molecular mechanism underlying desensitization, essentially analogous to the model for allosteric properties of enzymes. But so far there is no direct proof of multiple binding sites on receptors, and the authors should also perhaps first demonstrate a direct coincidence between physiologically observed desensitization and inhibition of binding in vitro.

\section{BEHAVIOUR

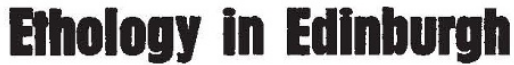

from our Animal Behaviour Correspondent

THE wide range of topics discussed at the twelfth international ethological conference held in Edinburgh from September 7 to 15 reflects the diversity of interests of ethologists. The first morning of the conference was devoted to the neurophysiological mechanisms underlying sequences of invertebrate behaviour, and several speakers, including $\operatorname{Dr}$ A. O. D. Willows (Washington University), showed that patterns of overt behaviour may in some cases arise from patterns of impulses originating in particular neurones. Other plenary sessions covered imprinting, behaviour of social insects and orientation. Dr W. T. Keeton (Cornell University) reviewed the most recent evidence on the homing ability of pigeons and concluded that biologists simply do not understand how these birds are able to find their way home. Displacement activities (behaviours appearing "out of context" or at least where ethologists don't expect to find them) were discussed by Dr P. Sevenster (Leiden University) and Dr D. J. MacFarland (University of Oxford).

Professor N. Tinbergen (University of Oxford) stressed the importance of investigating not only the causation of behaviour but also its adaptedness-how it helps the animal to survive-and Professor K. D. Roeder (Tufts University) pointed out that this applies as much to physiology ("behaviour below the skin") as to ethology. As an illustration of the interaction between these two disciplines, he described the violent escape response of a sphingid moth to ultrasound, a response which he has recently found to depend on a novel type of sound receptor near the moth's mouth.

Dr R. P. Michael (Institute of Psychiatry) described work carried out at the Primate Research Centre at Beckenham which has revealed that the smell of certain substances in the vaginal secretions of female rhesus monkeys has the effect of dramatically increasing sexual activity in the males. Dr Michael is continuing this work on other species including humans.

For the first time, the conference included a representative from the Soviet Union. Dr D. K. Belyaev (Novosibirsk University) described the unexpected morphological and chromosomal changes that took place in a population of silver foxes selected primarily for behavioural traits.

During the afternoons three parallel sessions were held in different halls so that it was impossible for everybody to hear all of the hundred or so contributions. Judicious flitting from one room to another, however, did enable one to learn of the ability of electric fish to recognize the sex of other individuals on the basis of the frequency of their electrical discharge (Dr C. D. Hopkins, Rockefeller University), of the precision with which caddis fly larvae build their houses (Dr M. H. Hansell, University of Glasgow) and of the function of the "dance" that blowflies perform when they come across a drop of food (Dr M. C. Nelson, Tufts University), to mention just three from several noteworthy contributions.

\title{
Reactivity of Portland Cement Minerals
}

Of the two calcium silicates, which form the bulk of Portland cement, $3 \mathrm{CaO} . \mathrm{SiO}_{2}$ is much more reactive than $\beta 2 \mathrm{CaO} . \mathrm{SiO}_{2}$. Both these phases, however, develop similar ultimate strengths on hydration and, from the manufacturing point of view, cement richer in $\beta 2 \mathrm{CaO} . \mathrm{SiO}_{2}$ is easier and cheaper to make than a cement richer in $3 \mathrm{CaO} \cdot \mathrm{SiO}_{2}$. Various empirical attempts have thus been made to increase the reactivity of $\beta 2 \mathrm{CaO} . \mathrm{SiO}_{2}$ without gaining any fundamental understanding of the factors controlling the intrinsic reactivity of the minerals. In a communication to be published next Monday in Nature Physical Science, Ramachandran and Sereda have applied the Hedvall effect to gain some understanding of this difference in reactivities of $\beta 2 \mathrm{CaO} . \mathrm{SiO}_{2}$ and $3 \mathrm{CaO} \cdot \mathrm{SiO}_{2}$.

$\mathrm{AgNO}_{3}$ has a phase transition point at about $190^{\circ} \mathrm{C}$. When a mixture of $\mathrm{AgNO}_{3}$ and a reactive material, for example $\mathrm{CaO}$, is cycled through this transition temperature a reciprocal pair forms very quickly. The authors have taken advantage of this fact in determining the reactivities of different minerals that may be present in Portland cement. The authors heated mixtures of $\mathrm{AgNO}_{3}$ and an individual cement mineral (or fully hydrated $3 \mathrm{CaO} . \mathrm{SiO}_{2}$ ) in a DTA (differential thermal analysis) apparatus and esti- mated the amounts of $\mathrm{AgNO}_{3}$ used up to form reciprocal pairs in each case. From these data they calculated the quantities of $\mathrm{Ca}$ ions that took part in each case. For $\mathrm{CaO}$ and $\mathrm{Ca}(\mathrm{OH})_{2}$, all the $\mathrm{Ca}$ ions took part in the reaction, but in the case of $3 \mathrm{CaO} \cdot \mathrm{SiO}_{2}$ and of $\beta 2 \mathrm{CaO} \cdot \mathrm{SiO}_{2}$ only 27 per cent and 6 per cent respectively of the $\mathrm{Ca}$ ions were involved. The presence of a higher proportion of more reactive $\mathrm{Ca}$ ions in $3 \mathrm{CaO} . \mathrm{SiO}_{2}$ than in $\beta 2 \mathrm{CaO} . \mathrm{SiO}_{2}$ seems to account for the higher reactivity of $3 \mathrm{CaO} . \mathrm{SiO}_{2}$. The authors then infer that "in tricalcium silicate all $\mathrm{Ca}$ ions are not equivalent, a part of it being more reactive".

The origin of this high reactivity of some of the $\mathrm{Ca}$ ions in tricalcium silicate is not so obvious. In the structure of $3 \mathrm{CaO} . \mathrm{SiO}_{3}$ (Jeffery, Acta Cryst., 5, 26 ; 1952), all the $\mathrm{Ca}$ ions are surrounded by six oxygen ions. In $\beta \mathrm{CaO} . \mathrm{SiO}_{2}$ (Midgley, Acta Cryst., 5, $307 ; 1952$ ) half of the $\mathrm{Ca}$ ions have six oxygen ions as first neighbour and the other half have eight. Thus origins of the higher reactivities of some of the $\mathrm{Ca}$ ions in different calcium silicates seem to be extra-structural, and they may not be directly related to the intrinsic reactivities of different calcium silicates. The origin of the difference in reactivities of the cement compounds thus still remains unexplained. 